\title{
Toward a Global View on Suburban Gentrification: from Redevelopment to Development
}

\author{
Delik Hudalah ${ }^{*}$ and Nabilla Adharina \\ School of Architecture, Planning and Policy Development, Bandung Institute of Technology, Indonesia.
}

Received: 2018-07-13

Accepted: 2019-03-13

Keywords:

gentrification;

suburb;

displacement;

redevelopment

Corespondent Email:

d.hudalah@sappk.itb.ac.id

\begin{abstract}
The gentrification literature, which is originated in the urban context, has now extended to suburb. Using content analysis on previous related case studies, this article shows that suburban gentrification is not necessarily a natural phenomenon resulting from disinvestment as the neighborhood lifecycle approach commonly suggests. As long as there is a development trigger, the suburb can gentrify anytime as it generally has a lower land value and a lower risk than urban area. The private sector and government play a key role in initiating and facilitating it to happen. In suburban context, the impacts of gentrification is complex, entailing varying negative and positive implications for the physical environment, the economies, and the society.
\end{abstract}

() 2019 by the authors. Licensee Indonesian Journal of Geography, Indonesia.

ditions of the Creative Commons

Attribution(CC BY NC) licensehttps://creativecommons.org/licenses/by-nc/4.0

\section{Introduction}

Gentrification is a fundamental concept explaining the links between socioeconomic succession and land use change. First coined by Glass (1964), gentrification referred to structural processes of neighborhood changes involving the displacement of original working class occupiers and their whole social character by those of higher socioeconomic status. This initial illustration presented gentrification as a response to 'a combination of neglect and concerted disinvestment by investor, due to high risk and low rates of return, initiated a long period of deterioration and lack of new capital investment' (Smith, 1979, p. 542). Previously, Smith's rent gap theory was widely used to explain gentrification occurring in urban areas. However, several studies have displayed that suburbs may also experience gentrification (Charles, 2011; Huang, 2010; Lucy \& Phillips, 2001; Niedt, 2006; Parlette, 2012; Prouse, Grant, Ramos, \& Radice, 2015; Streetar, 2013; Wulff \& Lobo, 2009).

In a subsequent stage of gentrification's conceptual development, Smith (1987) associated a decaying neighborhood with an object of real estate speculation. Likewise, the accompanying systematic replacement of this state was seen as a commodification process linked to the movement of capital. Smith (1979) provided an economic explanation of how these displacement and replacement occurred, arguing that the period of decay reflected the emergence of a 'rent gap' whereby there was a growing disparity between the actual and potential, 'highest and best', use of land. The emergent gap was seen to represent a profitable opportunity for various parties such as developers, landlords, tenants, and real estate agents to reinvest in and redevelop decaying neighborhood (Smith, 1979).

Smith's economic explanation indicates that the rent gap as a moment of reinvestment is a 'temporal' rather than 'spatial' concept. Land values tend to change in a long economic cycle. Their most rapid increase occur during periods of rapid capital accumulation and their decline temporarily happen during slumps (Smith, 1979). Reinvestment by developers may happen as long as spatial development is possible and relatively cheap. It is generally easier for developers to move their capital to new undeveloped areas and not to built-up areas because their redevelopment costs will be too high. In light with this, gentrification should not be seen as a phenomenon exclusively associated with the urban areas (Hudalah, Winarso, \& Woltjer, 2016). The phenomenon can also be found in other types of spatial location with lower development intensity, including suburbs. We argue that suburban gentrification tends to be initiated by the private sector and facilitated by government and has given varying implications for the physical environment, the economies, and the society.

Suburb is here loosely defined as an area on the fringe or outside the core of concentrated city and located in metropolitan area (Forsyth, 2012). In the metropolitan context, suburbs have become a place for accumulating capital that moves outward from urban areas (Streetar, 2013). The low price of land in suburbs offers people who work in urban areas an interesting place to live. Suburban development usually begins with the rising of population growth that results in the increase demand for space. As the next stage, suburbia may transform into post-suburbia in which the suburbs gain its functional independence as the number of employment space grows and surpasses that of the residential space (Borsdorf, 2004).

This article aims to explain why and how gentrification takes place in suburbs and how it can be differentiated from its urban counterpart. In doing 
so, we review and revisit previous studies related to gentrification in suburban, outer city, exurban, urban fringe and peri-urban contexts. Our analysis takes a global perspective by comparing key previous studies conducted in Europe, North America, and Australia, China, India and Southeast Asia. The previous works are used to picture a global perspective on suburban gentrification by seeking commonalities between the developed West and emerging Asia. Particularly, we employed content analysis on those works to identify approaches to and elements of suburban gentrification

The article is developed into five main sections. Following this introduction, we outline possible approaches to suburban gentrification. Later, we identify the key elements of suburban gentrification, including displacement and alteration, and their key players. As a further attempt to understand this suburban gentrification, we explore its negative and positive impacts. Finally, the last part concludes our discussion.

\section{Methods}

The main data used in this study is secondary data, referring to data gathered or created by previous studies for new research's objective (Bishop \& KuulaLuumi, 2017). We collected several case studies related to gentrification in suburban, outer city, exurban, urban fringe and peri-urban contexts from the developed West (North America and Australia) and emerging Asia (China, India and Southeast Asia, namely Indonesia and Vietnam). The multiple case studies were employed to generate and synthesize common characteristics of suburban gentrification.
This study uses qualitative data analysis. The analytical process is divided into three main steps. First is outlining the original idea of the previous studies to gain an objective understanding of their research's scopes. Second, we reduce the data and information into key categories through content analysis. The analytical results include process and causes of gentrification, main actors involved, and the impacts of suburban gentrification. Finally, we develop approaches to and elements of suburban gentrification.

\section{Result and Discussion}

This part is divided into three main discussions. They are approaches to suburban gentrification, elements of suburban gentrification, and the last discussion is the impact of suburban gentrification.

\section{Approach to Suburban Gentrification}

Previous studies on gentrification in suburban context can be clustered into four main approaches (Table 1). The first is the neighborhood life cycle approach, which is characterized by declining process and mostly found in the inner city context. The second approach highlights how megaproject results in gentrification without any moment of decline. The next approach emphasizes suburban gentrification as an impact of cultural alteration. The last one is institutional approach, which views suburban gentrification as the result of interactions between various actors, including their interests. The further explanation on each approach is discussed in the next part.

Table 1. Previous works on suburban gentrification

\begin{tabular}{|c|c|c|c|c|c|}
\hline \multirow[t]{2}{*}{ Case study } & \multicolumn{5}{|c|}{ Approach } \\
\hline & Housing-cycle & $\begin{array}{l}\text { Mega } \\
\text { Project }\end{array}$ & Redevelopment & Cultural & Institutional \\
\hline $\begin{array}{l}\text { Migration in the Inner West Melbourne, } \\
\text { Australia (Van Hulten, 2010; Wulff \& } \\
\text { Lobo, 2009) }\end{array}$ & $\sqrt{ }$ & & & & \\
\hline $\begin{array}{l}\text { Bangalore-Mysore IT corridor, India } \\
\text { (Lees et al., 2016) }\end{array}$ & & $\sqrt{ }$ & & & \\
\hline $\begin{array}{l}\text { Land development in Quanzhou, China } \\
\text { (Leaf, 2002) }\end{array}$ & & $\sqrt{ }$ & & & \\
\hline $\begin{array}{l}\text { New town project in Phu Gia, Vietnam } \\
\text { (Leaf, 2002) }\end{array}$ & & $\sqrt{ }$ & & & \\
\hline $\begin{array}{l}\text { Cultural differentiation in Borough of } \\
\text { Queens, New York City (Huang, 2010) }\end{array}$ & & & $\sqrt{ }$ & & \\
\hline $\begin{array}{l}\text { Suburb's imaging in Dundalk, Baltimore } \\
\text { (Niedt, 2006) }\end{array}$ & & & $\sqrt{ }$ & & $\sqrt{ }$ \\
\hline $\begin{array}{l}\text { High-income residential development } \\
\text { in a northern suburb of Bandung City, } \\
\text { Indonesia (Hudalah et al., 2014) }\end{array}$ & & & $\sqrt{ }$ & & $\sqrt{ }$ \\
\hline
\end{tabular}


The neighborhood life-cycle approach

The moment of decline can be an important element in explaining why suburban gentrification occurs. The declining moment, as introduced by Hoover and Vernon (1962), is seen as a phase in the neighborhood life-cycle. In general, the neighborhood life-cycle process comprises birth, growth, ageing, decline, and then abandonment phases. This process occurs and repeats over time and takes a relatively long time. By location, the neighborhood life-cycle approach generally starts from but does not stop in urban centers. Using Hoyt's (1939) filtering process of neighborhood, Streetar (2013) explained that the neighborhood lifecycle processes could also shift towards suburbs. First, a decreasing prospective return of property investment may result in urban center decline. Following the transition in population composition into lowerincome groups, the urban neighborhood transforms into an undesirable place characterized by among other increase of crime rate and decrease of safety and social service levels. As their land value reaches the lowest level, a rent gap is created and gentrification occurs. That process re-emerges over time and shifts from the urban center outward. In turn, suburbs also become a place that experiences gentrification. A wellknown illustration of suburban neighborhood life-cycle process can be found in the case of suburban Melbourne (Van Hulten, 2010; Wulff \& Lobo, 2009). In the 1970s, Melbourne's urban core experienced gentrification for the first time (Wulff \& Lobo, 2009). The movement was associated with an influx of foreign students to the city center. These skilled migrants deemed to contribute greatly to the excellence of Australian's education sectors.

In the initial phase of the gentrification, the Inner West, a Melbourne's suburb, merely consisted of an ordinary local settlement. It was physically dominated by heavy industrial activities, around which cheap houses for manufacturing workers were found. Three decades later, the suburb transformed into an expansion area of Melbourne. The population and economic growth in the Inner Melbourne shifted the gentrification from the city center to the Inner West. University and non-university graduates left the city center to seek more affordable houses in the suburb. A growing number of overseas students followed by the need for sufficient accommodation finally generated the competition between the overseas students and the local people. In 2001, 50.5\% of the people from overseas already lived in the suburb. Since then, the Inner West became an attractive suburban place for foreign people, whose arrival reached $2.7 \%$ in 2006 (Van Hulten, 2010). Generally, the international migrants entering Melbourne's inner suburb were young singles or young couples (Wulff \& Lobo, 2009). Van Hulten (2010) found that between 2001 and 2006 the residents who hold bachelor degree increased by $8.2 \%$, the employed residents increased by $4.3 \%$, and the median households' income also increased from $\$ 275$ to $\$ 1117$. In the same fashion as that occurred in the city center, the original suburban residents were displaced from the Inner West and moved outside into outer suburbs to seek more affordable neighborhoods.

\section{The megaproject approach}

Suburban gentrification can also begin without any moment of decline. Typically, land values in suburbs are generally lower. Parcels possessing lower value than their surroundings may have higher rent gap and, thus, their economic return potential will be more significant (Charles, 2011). Consequently, reinvesting capital in suburbs in some cases entails lower risk, and, moreover, higher investment return (Smith, 1979). However, undesirable conditions such as distance from city center and unfashionable architecture may reinforce the risk that will be burdened by investors or developers, unless, government interventions or subsidies exist to compensate the risk (Niedt, 2006). Those beneficial interventions strengthen the motivation of property owners or developers to reinvest in suburbs.

Megaprojects are complex large-scale projects and, thus, often require a high-level coordination of the state power and strategic partnership with the private sector. Megaprojects are carried out to serve the political interests of the nation-state and the local government, such as acceleration of economic growth and improvement of inter-regional connectivity. In the name of such wider 'public' interests, for megaproject proponents, a number of negative impacts such as displacement are at certain levels often considered acceptable (Zhang, 2002). In practice, however, the displacement, which occurs as a form of people's sacrifice for the 'public' interests, is often ignored by the state and developers (Goldman, 2011). In fact, the complicated relationship between the economic growth interests and the displacement has become a defining feature of gentrification. Therefore, in many cases, gentrification tends to be seen as part of the problem rather than a solution to economic stagnation and underdevelopment (Slater, 2006).

An IT corridor development project between Bangalore and Mysore, India, illustrates how a megaproject can drive suburban gentrification (Lees et al., 2016). This megaproject includes private townships development that will accommodate approximately 500,000 residents. Other important elements are industrial, commercial, farming and marketing centers. The megaproject also includes transport infrastructure such as highways, monorails, and expressways. It is still undergoing but there is significant progress such us the construction of an outer ring road. The development process entails mass displacement of not only the original residents but also communities' livelihoods, such as small-industry sectors and farm lands (Goldman, 2011). It is expected that over 1,500 of farmers and their families will probably be displaced (Raghuram \& Sundaram, 2009). 
Another case of suburban gentrification driven by a megaproject was a new town project in Phu Gia, Vietnam, which was developed by a Singapore-based subsidiary of Indonesia's largest developer, Ciputra Group. Phu Gia was one of the villages impacted by Hanoi urban economic expansion. One by one, Phu Gia's residents sold their plots through large-scale land transactions to informal brokers and urban entrepreneurs who speculated that the bracing of an area surrounding West Lake would be very potential and profitable to be developed (Leaf, 2002).

In a similar fashion, productive investment in fixed assets such as land has become a key contributor of China's economic development. Territorial expansion is a common strategy used by local government in China to accumulate land assets that makes them the de facto landlords (Shin, 2009, 2016). Leaf (2002) observed that Dong Mei, a suburb of Quanzhou, China, has experienced a rapid territorial expansion as the result of the city's expanding economies and a Chinese local government's entrepreneurial strategy of granting the land right to a developer. The affected village committees reinvested the compensation funds from the large-scale land transaction for the expansion of village-owned factories. This manufacturing expansion was aimed at capturing a growing market economy in the first half of the 1990s (Leaf, 2002).

\section{The cultural approach}

Culture is a basic and important contextual background in landscape production (Hackworth \& Rekers, 2005). Therefore, cultural preference is another factor that must be considered in addressing why and where gentrification occurs. In this regard, gentrification can be seen as a process of social differentiation by cultural factors (Zukin, 1989) or a response to cultural alteration (Munt, 1987). For example, Huang (2010) notes that before the 1980s, Flushing, a suburb of New York City, Borough of Queens, was predominantly a place for the white population. During the 1980s, more than 50 per cent of commercial firms closed and many demolitions were carried out. However, in the 1990s a Taiwanese small developer initiated a transformation of the decaying Flushing into a commercial-residential mix-used zone that reflects Taiwanese favorable place for living. It resulted in an increasing number of incoming Asian immigrants who left Manhattan to avoid the impact of the 1990s recession.

In addition to the architectural style applied in developing Flushing, the incoming of Asian immigrants were also related to the Asian cultural value that prefers to live in the neighborhood with a high concentration of Asians (Huang, 2010). As the proportion of the white population decreased, gentrification increased the proportionate number of the minority. Gentrification re-created a homogenous racial composition in Flushing, albeit one quite different from that of the 1980s. Today immigrants of Asian origins, including not just Taiwanese but also Chinese, Korean, Indian and Filipinos have dominated the suburb's demography. The suburb has transformed into a so-called ethnic- based enclave, a prestigious living place for Asian elites. The Asian immigrants perceived that, by moving to Flushing, they would detach themselves from the traditional working-class image that has long been associated with those lived in Chinatown, Manhattan.

\section{The institutional approaches}

Institutionalists concern both formal and informal institutions' impact upon individuals and the interaction between individuals and institutions (Rhodes, Binder, \& Rockman, 2008; Thissen \& Walker, 2013). Niedt (2006) argued that the interaction among political interests, behavior, organizational structure, norms and rules contributed to the process of gentrification in Dundalk, an inner-ring suburbs of Baltimore. Until a revitalization project came, Dundlak was considered as an isolated suburb dominated by race-based lowclass communities. The project was supported, by not only developers and county government but also the white homeowners motivated by revanchist politics. They regarded gentrification as a tool to improve the suburb's image. Niedt (2006, p. 104) stressed that 'progentrification discourse enables white homeowners and merchants to avoid (often simplistic) accusations of racism by emphasizing the expected positive qualities of incoming residents'. They particularly blamed a group of welfare programme's recipients for the declining situation occurring in Dundalk. The rise of housing prices and property taxes frightened the lowincome households and African American enclaves, which later might force them to move.

Hudalah et al. (2014) attempted to extend the relevance of institutionalist approaches in explaining gentrification in Punclut, a northern suburb of Bandung City, Indonesia. During the 1940s, or the late Dutch colonial era, North Bandung Area was a tea plantation owned by a Dutch company. After the independence, following the nationalization of Dutch assets, a large part of Punclut became neglected and gradually occupied by local people who previously worked in the plantation company. Due to its topographical and geological locations, Punclut and its surroundings (the North Bandung Area) had the function as a water catchment area for the city. Opportunities for urban development were restricted in this area. There were also multiple claims of land tenure in the area, adding to the complexity of Punclut and contributing to the stagnation of its redevelopment.

After decades of stagnation, a public-private partnership-based revitalization project that largely promoted high-income residential development was carried out in 2004. Loss of environmental amenity and displacement of local people and their livelihoods were the inevitable consequences. There were key formal and informal rules and regulations that contributed to both enabling and hindering the project's realization. First, deregulation packages in finance and property industries increased land speculation and triggered the 1990s Indonesia property boom, including in Bandung Metropolitan Area. As a result, from 1992 to 1996 or within only 4 years, the land acquired by private 
developers in Punclut and its surroundings increased from only 586 ha to 2832 ha. Later, in the 2000s, a decentralization policy gave local government more power in urban planning and development policies, leaving higher tiers of government structure with little authority in mitigating the wider implications of local policies. Nevertheless, it also revealed that informal coalition building by planners and environmentalists and activation of local knowledge help prevented the wider implications of the gentrification at the regional level (Hudalah et al., 2016).

\section{Elements of suburban gentrification}

Based on the four approaches built in the previous part, we identify four main elements describing suburban gentrification. First, we learn that suburban gentrification results in physical and socioeconomic alteration. Second, displacement especially driven by megaproject is an important element differentiating suburban gentrification from its inner city counterpart. The last element is key involved actors, who can be divided into rent seeker (such as developer) and facilitator (namely government).

\section{Physical and socioeconomic alteration}

One of the elements of gentrification includes physical upgrading of the neighborhood, notably alteration of height and density of buildings. Physical changes are also related to intensification or restructuring of socio-economic activities of the neighborhood (see Table 2). The redevelopment pulls the higher-income people to move into the area. As the land value and land rent increase, the original residents, who are socioeconomically more vulnerable, are conditioned to move to less expensive neighborhoods. Because of redevelopment, physical upgrading generates many changes in the neighborhood. Redevelopment often boosts the neighborhood to have higher density than before. As land rent increases, obsoleted houses are demolished and replaced by higher density buildings (Hufbauer \& Severn, 1974).

In the case of the gentrification of the Inner West in Melbourne, physical upgrading can be seen through

Table 2. Dimensions of alteration in suburban gentrification

\begin{tabular}{ll}
\hline Dimension & Alteration \\
\hline Physical feature & $\begin{array}{l}\text { Higher density and/ or } \\
\text { higher building }\end{array}$ \\
Socioeconomic activity & $\begin{array}{l}\text { More intensive } \\
\text { Lesidential (rooming } \\
\text { house, flat); mixed use } \\
\text { (commercial and resi- } \\
\text { dential) }\end{array}$ \\
& $\begin{array}{l}\text { Younger, middle-income, } \\
\text { homogenous, skilled, } \\
\text { small-sized family }\end{array}$ \\
\hline
\end{tabular}

the type of its land use. The landlords in the Inner West were likely to exploit their houses into rooming houses, local caravan parks, and commercial buildings (Van Hulten, 2010). Meanwhile, gentrification in Flushing, Queens, generated land use change from commercial areas into mixed uses, including conflating commercial use and residential use (Huang, 2010). A small private developer initiated to create the new Flushing by applying Taiwanese values into urban development practice. He mixed commercial use with residential use. As a result, Flushing became a desirable location for other small developers and households, and by 1998, it transformed into the fifth largest shopping district in New York City. Huang (2010) calculated that between 2000 and 2006 the land rent had increased from $\$ 832$ to $\$ 1160$ and the housing value had increased from $\$ 269,043$ to $\$ 535,700$.

Meanwhile, in the case of revitalization in Punclut, North Bandung Area, the suburban kampongs (irregular settlements) and their seasonal agricultural land were more likely to change into leisure and recreation areas and elite housing estates (Hudalah et al., 2016). The reason for this land use alteration was twofold. First, North Bandung Area was associated with beautiful hills and cool climate. Second, Punclut was located in reasonable proximity to the city center of Bandung, which is one of country's most favorite tourist destinations. The project site was designated for garden houses, consisting of lower-density houses that signified the exclusivity and prestige of a higherincome neighborhood (Hudalah et al., 2016). Similar physical alteration happened in Phu-Gia, Vietnam. First, small houses and gardens dominated Phu-Gia's land use. Later, they were transformed into luxurious villas with exclusive facilities such as restaurants and bars (Leaf, 2002).

Redevelopment makes the value of land to be higher than before. The residents who still want to live there must be able to pay the higher rent or land value. In addition, the landlords also will be more selective and carefully choose their tenants to guarantee they are able to pay the rent even though the fee is increased. Consequently, the new resident's characteristics mostly have higher incomes than the previous ones, which can be indicated from their skills and ages. For example, households' characteristics who displaced the preceding residents in Inner West were educated, employed, and medium to high-income residents (Van Hulten, 2010). In addition, suburban gentrification may also have a correlation with the ethnic preference. Flushing case has shown that gentrification may contribute to the creation of ethnic enclave. After becoming a living place for the white people, gentrification led Flushing to become the China Town of the U.S. (Huang, 2010).

\section{Displacement \\ Displacement is sometimes difficult to resist when there is a development or redevelopment}


project. Although redevelopment may increase the quality of the neighborhood, displacement tends to be unfavorable for lower-income residents. Displacement itself can be defined in terms of a unit of housing, individual, or neighborhood (Marcuse, 1985). Gellert and Lynch (2003) outlined that megaproject planning and development processes entailed two major types of displacement: primary and secondary displacements. The primary (direct) displacement is more predictable and normally an integral part of megaproject. The examples include eviction and resettlement of householders. Meanwhile, secondary (indirect) displacement generally has uncertain nature and temporary consequences. The examples include property loss, unemployment, economic decline, and social disconnections.

One of the several types of the primary (direct) displacement is displacement of original residents (Gellert \& Lynch, 2003). In fact, this type of displacement, particularly of lower-income residents, is a basic element of gentrification (Kennedy \& Leonard, 2001). In the context of suburban gentrification, we can distinguish this type of displacement into two forms: direct last-residence displacement and displacement pressure.

Marcuse (1985) divides direct last-residence displacement into two categories: physical and economical. The physical type occurs when the residents move out because the landlords cut off the building's utilities, such as heat and electricity. Meanwhile, the economic type will emerge if the landlord increases the rent beyond the tenants' ability to pay. As an illustration, in the case of Cook County, an inner-ring suburb of Chicago, the price of sales increased three times than its original property price (Fine \& Lindberg, 2002). This type of displacement can also be encouraged by landlord's action. In the case of Inner-West Melbourne, the landlords had particular criteria for selecting their tenants (Van Hulten, 2010). They instrumentally increase the rent price in order to meet their criteria of favoring middle-income households from young professionals. As the result, the low-income residents needed to trade down their accommodation and finally moved to other locations.

Direct last-residence displacement may also be associated with the result of power struggle between the proponent and opposition of suburban gentrification. In the case of North Bandung Area, the right of marginalised and low-income residents were undermined by the issuance of a large-scale land development permit and a local land use plan revision (Hudalah et al., 2016). In other cases of megaproject, direct last-residence displacement includes residences who were forced to move by selling their land under government or developer pressure. In the case of IT Corridor development project in suburban Bangalore, it was reported that many farmers desperately sold their land to the government at a very low price (Goldman, 2011).
Meanwhile, displacement pressure happens when groups of residents live under pressure of neighborhood transformation that makes the area less livable for them. The pressuring conditions force them to move as soon as they can. Displacement pressure can be regarded as a follow up implication of direct last-residence displacement as it is experienced by the residents after other residents have moved. A general reason for the remaining households to move is not necessarily economical but can be psychological such as a feeling of losing their community (Van Hulten, 2010).

\section{Key actors involved in suburban gentrification}

The actors involved in promoting suburban gentrification can be divided into two groups. The first key actors are those involve in the development process such us developers and bankers or other financial agents. The second group is the public sector who facilitates the developers and bankers through several means. Gentrification starts with transformation of a suburb's image. Suburbs in the first place have low-density land uses. Later, they turn into an attractive place with more intensive activity and better connectivity to urban center. If we try to think who is behind the redevelopment, the player that will come up easily from our mind is the private developer. However, in line with Streetar (2013), the representative of the real estate interests needs to be extended to also include homeowners, landlords, lenders, and real estate agencies (see Table 2).

Developers are the actor who have the willingness and ability to mediate global demand and become the forerunner in suburban neighborhood development or redevelopment (Niedt, 2006). Generally, developers play roles in demolition, construction, services, soft costs, and selling (Streetar, 2013). However, to act rationally and obtain quite high profit from the sales of property developed in suburbs, the developers need to consider many conditions. In addition to suburban rent gap, physical conditions such as the connectivity to urban center and existing infrastructure are also taken into their consideration. Furthermore, Niedt (2006) mentioned that the relationship between developers and county government is important for the continuity of project development.

Developers create exclusive image and impression of the new suburbs by, for instance, developing luxurious residential enclave. The case of North Bandung Area suggests that developers have the ability to reshape the suburban neighborhoods into ones that can only be accessed by particular kind of residents, especially higher-income residents (Hudalah et al., 2016). In addition, as depicted by the Inner-West gentrification, landlords can also accelerate gentrification through market discrimination such as the preference of youngmiddle income renters (Van Hulten, 2010). It is evident that both developer and landlord have a significant role in direct-last resident displacement. 
In many cases of suburban gentrification, governments can also make significant - although largely indirect - contributions. Through marketoriented policies, national and local governments often facilitate and create opportunity for developers to invest in land and property development. Redevelopment leading towards suburban gentrification is often resulted from coordination between private developer interests to make profits and government desires to improve urban economies (He, 2007). The issuance of development rights can be seen as a strategic action by government to prevent neighborhoods from declining while at the same time capturing global capital flow and finally competing at a global scale. Several attempts are experimented by government to attract both local and global capital into designated metropolitan areas, including settlement and transport infrastructure development. In the case of Phu Gia, such attempts attracted the Indonesia's biggest developer to move their capital and transformed the Hanoi's suburb into an attractive place for business (Leaf, 2002).

In the case of Inner West, Melbourne, one of various factors that trigger gentrification was the regulatory system. There were housing subsidies from federal and state government to improve housing affordability that contributed to increase the number of housing ownerships not only in the Inner-West but also in different states in Australia (Van Hulten, 2010). In addition, Van Hulten (2010) argued that the national taxation system in Australia had given a high incentive for property investment and it automatically generated the number of borrowing incentive and increased assets speculation. Furthermore, in countries with strong developmental state tradition, government can proactively contribute in suburban land development. The process normally starts when government promotes housing construction. For example, in order to respond to a displacement in the city centre of Shanghai, the Chinese local government would facilitate the residents to move by offering resettlement and cheap land in an inner suburb (He, 2007). Moreover, since the municipal government play as the de facto landlord, land asset accumulation, including land in suburbs, is necessary to increase economic development (Shin, 2016).

\section{Impacts of suburban gentrification}

There will always be negative impacts resulting from gentrification (Van Hulten, 2010). Amongst others, displacement of disadvantaged residents is often viewed as a major negative impact of gentrification (Murdie \& Teixeira, 2010). In addition, in the case of Inner-West, gentrification has produced inequality in Melbourne. This occurred because, first, one group displaced another group, forcing the latter to move from the Inner-West neighborhood to Brimbank, an Australia's disadvantaged municipality located in the outer Western Melbourne (Van Hulten, 2010). Disadvantages were experienced not only by the people who moved, but also by longstanding residents who had to deal with greater expenses for services, rent, and even for food. Elderly and people living with disability felt the greatest impact because they might only rely on their pensions or even social security services.

Several studies have shown that urban gentrification displaces ethnic minorities (Boyd, 2008; Lees, 2000; Niedt, 2006; Schaffer \& Smith, 1986). However, suburban gentrification may reveal a contrasting story. For instance, a 'white flight' phenomenon instead featured suburban gentrification in Flushing, Queens, in which the white population decreased due to the arrival of Asian minority. In addition to unavoidable displacement of local people, an increasing attention has been given to the impact of megaproject on environmental displacement. In the case of the IT Corridor in India, the large-scale physical development displaced rock, soil, hydrological patterns, natural habitats, and plant and animal species (Gellert \& Lynch, 2003). The environment is often sacrificed to meet the demand of wealthier residents who desire highrise apartment, exclusive markets, and entertainment centers. As long as new residents come, infrastructure will continue to be developed.

Nevertheless, the impact of suburban gentrification is not always negative. It may also benefit several selected actors and the environment. Revitalization planning initiated by government may have the intention to prevent the suburban land from becoming obsolete, unproductive or unattractive over extended periods of time. Furthermore, improved and stabilized neighborhood conditions that are attractive for higher-income residents will increase property tax revenues, from which government can gain funds for economic development, such as in education sector (Biro, 2007; Charles, 2011; Murdie \& Teixeira, 2010). Suburban redevelopment can also be used as an antisprawl planning strategy (Charles, 2011). Redeveloped neighborhood is also attractive for private developers, with whom government can cooperate to develop infrastructure, including those that integrate the suburbs with city centers. In turn, redeveloped suburbs can transform into vibrant places to live due to longterm population and economic growth and improved condition of urban areas.

The impacts of suburban gentrification depend on the new characteristics embraced by the gentrified neighborhood. Poorly planned redevelopment may create an uncontrolled growth of new residents and resettlement, which will just reinforce existing socioeconomic problems. Meanwhile, successful redevelopment will enhance not just the suburb's economies but also the economic development of the affected regions. For example, gentrification in the Inner-West contributed in improving the education sector of Melbourne and in making education becoming Victoria’s largest economic sector (Van Hulten, 2010). 


\section{Conclusion}

In this article, we have proposed four approaches to suburban gentrification process: the neighbourhood life-cycle approach, the megaproject approach, the cultural approach, and the institutional approach. Despite differences, all these approaches suggest that, in suburban context, gentrification tends to shift from piecemeal redevelopment to large-scale development perspective. First, the neighbourhood life-cycle approach emphasises that gentrification is rather a natural phenomenon. For this approach, gentrification shall begin with a moment of decline caused by the decreasing prospective return of investment in urban areas, followed by disinvestment, devalorisation, and redevelopment. All these phases shift outward from urban areas towards suburb in a relatively long period. However, not all of suburban gentrification is triggered by a moment of decline of already developed neighbourhood. In the fast-growing metropolitan area, the land value of undeveloped suburb is generally lower than that of congested city centre. Moreover, the value of the undeveloped suburban land may experience a moment of decline following which neighbourhood can be developed in the first place. Further explanations to these types of gentrification are suggested by the megaproject, cultural, and institutional approaches.

(Re)development and displacement alter the physical and socioeconomic conditions of suburban neighborhood. Physically, it changes building density in the neighborhood. The activity created also becomes more intensive than before. Moreover, the land in the gentrifying suburb is likely to be utilised for profitable activities such as commercial and mixed land uses, between residential and commercial uses. Other changing aspects are society and the economy. Higher land value, land rent, and services created by redevelopment makes the criteria for selecting resident candidates more restricted. They utterly have higher income than the previous ones. They are mostly in productive age, with an increasing number of employees. It also reveals that gentrification can be related to ethnic preference. Several cases show that suburban gentrification increases the number of minorities, and neighbourhood with a small number of minorities tend to be difficult to gentrify.

Our comparative analysis suggests that there are also key players that actively promote or facilitate suburban gentrification to happen. In both development and redevelopment, developers, real estate agents, and lenders are involved. In addition, rent price decision by landlords and homeowners also take part in the criteria selection of what kind of residents who are willing and able to rent their buildings. Meanwhile, governments at all levels have facilitated suburban gentrification by developing neglected land, strengthening suburbs' transport and infrastructure connectivity to city centers, and designing pro-market regulatory frameworks and easing investment bottlenecks. These attempts can be seen as a government's strategy to attract both local and global capital flows while at the same time preventing the suburban neighborhood quality from decaying

Biro (2007) has warned us that gentrification has a double-edged sword. Gentrification may contribute in improving the productivity of neglected suburban land and suburbs' attractiveness. Suburbs are no longer far behind the city centers in terms of physical and socioeconomic advancement. Moreover, the developed suburbs may give higher contribution to local, regional and national economies than urban centers. Whilst benefitting few selected groups, suburban gentrification entails the displacement of other - often larger sections of the communities. Physical and socio-economic transformation associated with suburban gentrification always results in the displacement and marginalization of less advantaged groups. Therefore, suburban gentrification will continue to become a dilemma for the communities and government. It becomes an issue as to whether there can be suburban redevelopment or development without gentrification and its associated displacement.

\section{References}

Biro, J. (2007). Gentrification: deliberate displacement, or natural social movement? The ParkPlace Economist, 15(1), 42-46.

Bishop, L., \& Kuula-Luumi, A. (2017). Revisiting qualitative data reuse: A decade on. Sage Open, 7(1), 2158244016685136.

Borsdorf, A. (2004). ON THE WAY TO POST-SUBURBIA? Insights on Outskirts, 7.

Boyd, M. (2008). Defensive Development The Role of Racial Conflict in Gentrification. Urban Affairs Review, 43(6), $751-776$.

Charles, S. L. (2011). Suburban Gentrification: Understanding the Determinants of Single-family Residential Redevelopment, A Case Study of the Inner-Ring Suburbs of Chicago, IL, 2000-2010. Cambridge, MA: Joint Center for Housing Studies of Harvard University.

Fine, A. S., \& Lindberg, J. (2002). Protecting America's historic neighborhoods: taming the teardown trend. Washington, DC: National Trust for Historic Preservation.

Forsyth, A. (2012). Defining suburbs. Journal of Planning Literature, 27(3), 270-281.

Gellert, P. K., \& Lynch, B. D. (2003). Mega-projects as displacements. International Social Science Journal, 55(175), 15-25.

Glass, R. (1964). Introduction: Aspects of change. In Centre for Urban Studies (Ed.), London: Aspects of Change. London: MacKibbon and Kee.

Goldman, M. (2011). Speculating on the next world city. In A. Roy \& A. Ong (Eds.), Worlding Cities: Asian Experiments and the Art of Being Global (pp. 229-258). West Sussex: Wiley-Blackwell.

Hackworth, J., \& Rekers, J. (2005). Ethnic Packaging and Gentrification The Case of Four Neighborhoods in Toronto. Urban Affairs Review, 41(2), 211-236.

He, S. (2007). State-sponsored gentrification under market transition the case of Shanghai. Urban Affairs Review, 43(2), 171-198.

Hoover, E. M., \& Vernon, R. (1962). Anatomy of a metropolis: The changing distribution of people and jobs within the new york metropolitan region. Garden City, NY: Doubleday. 
Hoyt, H. (1939). The structure and growth of residential neighborhoods in American cities. Washington, DC: Federal Housing Administration.

Huang, W. (2010). Immigration and Gentrification - a case study of cultural restructuring in Flushing, Queens. Diversities, 12(1), 56-69.

Hudalah, D., Winarso, H., \& Woltjer, J. (2016). Gentrifying the peri-urban: Land use conflicts and institutional dynamics at the frontier of an Indonesian metropolis. Urban Studies, 53(3), 593-608.

Hufbauer, G. C., \& Severn, B. W. (1974). The economic demolition of old buildings. Urban Studies, 11(3), 349351.

Kennedy, M., \& Leonard, P. (2001). Dealing with neighborhood change: A primer on gentrification and policy choices. Brookings Institution Washington, DC.

Leaf, M. (2002). A tale of two villages: globalization and peri-urban change in China and Vietnam. Cities, 19(1), 23-31.

Lees, L. (2000). A reappraisal of gentrification: towards a 'geography of gentrification'. Progress in Human Geography, 24(3), 389-408.

Lees, L., Shin, H. B., \& López-Morales, E. (2016). Planetary gentrification. Cambridge: Polity Press.

Lucy, W. H., \& Phillips, D. L. (2001). Suburbs and the census: Patterns of growth and decline. Brookings Institution, Center on Urban and Metropolitan Policy.

Marcuse, P. (1985). Gentrification, abandonment, and displacement: Connections, causes, and policy responses in New York City. Wash. UJ Urb. \& Contemp. L., 28, 195-240.
Munt, I. (1987). Economic restructuring, culture, and gentrification: a case study in Battersea, London. Environment and Planning A, 19(9), 1175-1197.

Murdie, R., \& Teixeira, C. (2010). The impact of gentrification on ethnic neighbourhoods in Toronto: A case study of Little Portugal. Urban Studies.

Niedt, C. (2006). Gentrification and the grassroots: Popular support in the revanchist suburb. Journal of Urban Affairs, 28(2), 99-120.

Parlette, V. M. (2012). On the Margins of Gentrification: The production and governance of suburban 'decline'in Toronto's inner suburbs. University of Toronto. Retrieved from https://tspace.library.utoronto.ca/ handle/1807/67308

Prouse, V., Grant, J. L., Ramos, H., \& Radice, M. (2015). Assessing neighbourhood change: Gentrification and suburban decline in a mid-sized city (Working Paper). Dalhousie University, Halifax.

Raghuram, G., \& Sundaram, S. S. (2009). Lessons from Leveraging Land: A Case of Bangalore Mysore Infrastructure Corridor (Working Paper No. 200902-04). Indian Institute of Management, Ahmedabad. Retrieved from http://indiatogether.org/campaigns/ bmic/bmicfaq.htm

Rhodes, R. A., Binder, S. A., \& Rockman, B. A. (2008). The Oxford handbook of political institutions. Oxford UniversityPress.Retrieved fromhttps://www.google.com/ 